\title{
BMJ Open Competing priorities in treatment decision-making: a US national survey of individuals with depression and clinicians who treat depression
}

\author{
Paul J Barr, ${ }^{1,2}$ Rachel C Forcino, ${ }^{1}$ Manish Mishra, ${ }^{2,3}$ Rachel Blitzer, ${ }^{2}$ Glyn Elwyn ${ }^{1,3}$
}

To cite: Barr PJ, Forcino RC, Mishra M, et al. Competing priorities in treatment decision-making: a US national survey of individuals with depression and clinicians who treat depression. BMJ Open 2016;6:e009585. doi:10.1136/bmjopen-2015009585

- Prepublication history and additional material is available. To view please visit the journal (http://dx.doi.org/ 10.1136/bmjopen-2015009585).

Received 3 August 2015 Revised 2 November 2015 Accepted 2 December 2015

\section{CrossMark}

\footnotetext{
${ }^{1}$ The Dartmouth Institute for Health Policy and Clinical Practice, Lebanon, New Hampshire, USA

${ }^{2}$ Geisel School of Medicine at Dartmouth, Hanover, New Hampshire, USA

${ }^{3}$ The Dartmouth Center for Health Care Delivery Science, Hanover, New Hampshire, USA
}

Correspondence to Dr Paul J Barr; paul.j.barr@dartmouth.edu

\section{ABSTRACT}

Objective: To identify information priorities for consumers and clinicians making depression treatment decisions and assess shared decision-making (SDM) in routine depression care.

Design: 20 questions related to common features of depression treatments were provided. Participants were initially asked to select which features were important, and in a second stage they were asked to rank their top 5 'important features' in order of importance. Clinicians were asked to provide rankings according to both consumer and clinician perspectives. Consumers completed CollaboRATE, a measure of SDM. Multiple logistic regression analysis identified consumer characteristics associated with CollaboRATE scores.

Setting: Online cross-sectional surveys fielded in September to December 2014.

Participants: We administered surveys to convenience samples of US adults with depression and clinicians who treat depression. Consumer sampling was targeted to reflect age, gender and educational attainment of adults with depression in the USA.

Primary outcome measures: Information priority rankings; CollaboRATE, a 3-item consumer-reported measure of SDM.

Results: 972 consumers and 244 clinicians completed the surveys. The highest ranked question for both consumers and clinicians was 'Will the treatment work?' Clinicians were aware of consumers' priorities, yet did not always prioritise that information themselves, particularly insurance coverage and cost of treatment. Only $18 \%$ of consumers reported high levels of SDM. Working with a psychiatrist (OR 1.87; $95 \% \mathrm{Cl}$ 1.07 to 3.26 ) and female gender (OR $2.04 ; 95 \% \mathrm{Cl}$ 1.25 to 3.34 ) were associated with top CollaboRATE scores.

Conclusions: While clinicians know what information is important to consumers making depression treatment decisions, they do not always address these concerns. This mismatch, coupled with low SDM, adversely affects the quality of depression care. Development of a decision support intervention based on our findings can improve levels of SDM and provide clinicians and consumers with a tool to address the existing misalignment in information priorities.

\section{Strengths and limitations of this study}

- This study aimed to identify information priorities for consumers and clinicians making depression treatment decisions via a US national survey of 972 consumers and 244 clinicians.

- To our knowledge, no other study of this scale has compared the information priorities of consumers and clinicians with regard to depression treatment decisions.

- The convenience sampling approach precludes true representativeness, though sampling quotas were in place to approximate the prevalence of depression among US adults on age and gender within our sample.

- The results from this study can inform the development of a decision support intervention to increase SDM and alignment of information priorities between consumers and clinicians facing depression treatment decisions.

\section{INTRODUCTION}

Treatments for individuals with depression are numerous, with multiple generations of antidepressant medications and psychosocial interventions such as cognitive-behavioral and problem-solving therapies now delivered both in person and online. ${ }^{1-5}$ These treatment options do not differ substantially in effectiveness, ${ }^{46}$ yet significant side effects are more commonly reported with the use of antidepressant medications. ${ }^{78}$ While consumers tend to prefer psychosocial therapies, ${ }^{9}$ $75 \%$ of consumers use antidepressant medication and only $43 \%$ use psychosocial interventions. ${ }^{10}$ In addition, individuals with depression often do not adhere to treatment, ${ }^{11-14}$ especially with antidepressants. ${ }^{12-14}$ While lack of access is an issue for some treatment options, misalignment between a consumer's preferred treatment and prescribed treatment can contribute to low adherence and is detrimental to the 
therapeutic alliance between consumer and clinician. ${ }^{15}$ Likewise, aligning treatment decisions with consumer preferences results in lower rates of treatment attrition, fewer missed appointments, higher consumer satisfaction and better clinical outcomes. ${ }^{16-18}$

Shared decision-making (SDM) aims to generate greater alignment between patient preferences and chosen treatments with a view to improving subsequent treatment outcomes. ${ }^{19}$ When individuals with depression are involved in SDM, treatment selection, adherence, satisfaction and outcomes are improved. ${ }^{18} 20{ }^{21}$ Yet many individuals with depression experience inadequate SDM. Solberg et $a l^{22}$ surveyed 1168 adults with depression in Minnesota and found moderate levels of SDM. Consumers who were older, who were in poverty, who were of poorer general health or who had been treated for longer than 6 weeks reported lower levels of SDM, although the generalisability of these results is limited given that all participants were from a primary care sample. Additionally, independent raters found very low levels of SDM across 287 audio-recorded encounters of standardised patients presenting to primary care practices with symptoms of depression. ${ }^{23}$

These low levels of SDM are not surprising: individuals with depression often are not given time to ask questions about treatments and are dissatisfied with the amount of information they receive. ${ }^{24}$ Decision support intervention tools (DESIs) have been suggested as a solution. ${ }^{25}$ DESIs increase patient knowledge about treatment options and have the potential to enhance consumerclinician communication. ${ }^{26}$ DESI use has been shown to help patients develop more informed, preference-led treatment choices. ${ }^{26}$ Issue cards, decision boxes and option grids are examples of brief tools for use during clinic visits that are shown to increase SDM. ${ }^{27}$ However, few DESIs have been designed and tested for English-speaking patients with depression, ${ }^{28}$ and those that focus exclusively on comparing medication options and do not include evidence about other equally effective psychosocial treatments. ${ }^{29}$ To date, only one DESI, developed and tested in German, includes information on medication and psychotherapy. ${ }^{30}$ Early studies of the existing DESIs are promising, indicating increases in consumer engagement, satisfaction, knowledge, reductions in decisional conflict and no difference in consultation time. ${ }^{29} 30$

DESI development requires an understanding of the information considered important by both healthcare consumers and healthcare professionals. A search for previous work addressing this issue did not identify any relevant studies.

We aimed to address this gap by identifying the information most important to consumers and clinicians when making depression treatment decisions and assess the extent of SDM in routine depression care as reported by consumers.

\section{METHODS}

\section{Participants}

We administered parallel cross-sectional national surveys between September 2014 and January 2015 to convenience samples of: (1) individuals who were currently being treated, were awaiting treatment or had previously been treated for depression; and (2) clinicians who had recently treated individuals with depression. Dartmouth College's Committee for the Protection of Human Subjects (CPHS) considered this project exempt from Institutional Review Board (IRB) review. All surveys were completed online and hosted by Qualtrics (Qualtrics LLC, Provo, Utah, USA).

\section{Consumers}

Consumers were eligible for inclusion if they had ever been diagnosed with, counselled about or treated for depression; were aged 18 years or older; resided in the USA; and were comfortable reading and writing in English.

\section{Clinicians}

Clinicians were eligible for inclusion if they counselled, diagnosed or treated a person with depression in the prior 12 months; practised in the USA; and were comfortable reading and writing in English. We define clinician to include primary care physicians (including internal and family medicine), psychiatrists, psychologists, psychiatric/mental health nurses, social workers and licensed professional counsellors.

\section{Recruitment}

Participants were recruited from convenience samples. Approximately 15 US-based healthcare organisations and consumer advocacy groups shared a hyperlink to the survey via email, listserv, social media (Facebook and Twitter) or personal communication (see online supplementary appendix 1 for details).

To ensure the sample of consumer respondents matched population distributions, we adopted recruitment quotas based on epidemiological data. ${ }^{31}$ These quotas helped to approximate the lifetime prevalence of depression among US adults with regard to age, gender and educational attainment. Similar data were not available for the clinician sample.

We used paid advertising via Facebook to target male consumers due to low survey uptake. We supplemented clinician recruitment with respondents from Qualtrics Panels (Qualtrics LLC, Provo, Utah, USA).

\section{Measures}

We developed a 53-item patient survey and a 63-item clinician survey (see online supplementary appendices 2 and 3). The surveys used a combination of validated, adapted and newly developed questions (more detail is provided below). The surveys were informally piloted with local clinicians, research staff and consumer 
representatives to assess survey duration, flow and ease of interpretation. Our approach modelled that of a recent survey investigating what matters most to individuals facing contraception decisions. ${ }^{32}$

\section{Patient survey}

The patient survey consisted of five sections: sociodemographics, health status, treatment experience, information priorities and SDM. The information priorities section consisted of 20 frequently asked questions (FAQs) deemed pertinent to depression treatment decision-making based on a literature review of peerreviewed journal articles, guidelines, existing decision support tools for depression and stakeholder input. Respondents were also given an opportunity to list additional information priorities within the survey. Sociodemographic questions were based on US Census items; ${ }^{33-36}$ questions on health status (comorbidities, current depression status) and treatment experience (treatment history, treating clinician) were developed for this study.

To assess information priorities, consumers were asked to rate 20 FAQs on a five-point Likert-type importance scale in response to the question, 'How important is each of these questions to you when choosing a treatment for depression?' Responses ranged from 'extremely unimportant' to 'extremely important' with an additional 'don't know what this means' response option. FAQs were divided into five blocks covering four content areas: the process of receiving treatment, lifestyle impact, side effects and financial considerations. The presentation of item blocks and items within blocks was randomised to avoid order effects. FAQs marked either important or very important were then included together on a subsequent webpage and ranked by respondents to ascertain the top five information priorities. The same process was followed for side effects: where 'side effects' were marked important or extremely important, respondents were asked to rank the top 5 from a list of 12 commonly reported side effects.

Consumers were also asked to complete CollaboRATE, a three-item validated measure of SDM, based on the most recent clinical encounter where depression was discussed. $^{37} 38$ The items are: (1) How much effort was made to help you understand your health issues? (2) How much effort was made to listen to the things that matter most to you about your health issues? (3) How much effort was made to include what matters most to you in choosing what to do next? Each of the three items was rated on a scale of 0 (no effort was made) to 9 (every effort was made).

\section{Clinician survey}

The clinician survey consisted of five sections: sociodemographics, practice setting, depression treatment experience, information priorities and SDM. To assess information priorities, clinicians followed the same process as consumers. Clinicians were asked to answer the questions from two perspectives: (1) their own perspective as clinicians ('In order to treat your patients' depression, how important do you think it is to discuss the following questions?'); and (2) the consumer perspective ('In your experience, how important do patients believe the following questions are when choosing a treatment for depression?').

\section{Analysis}

We used weighted scores to assess the five most important FAQs from each of three perspectives: (1) the consumer's perspective; (2) the clinician's personal perspective; and (3) the clinician's view of the consumer perspective.

FAQs within a respondent's top five were assigned weights based on their ranked order. The most important FAQ received five points, the second most important FAQ received four points, and so on, with the fifth most important FAQ receiving one point. FAQs outside the top five did not receive any points as respondents were asked to rank only their top five. Overall points per FAQ were summed and FAQs were rank-ordered; the FAQ with the most points was considered the most important. The same weighting procedure was used to rank side effects. Subgroup analyses of rankings were conducted by consumer age, gender and educational attainment, and by clinician practice specialty.

To assess the impact of consumers' sociodemographic characteristics and treatment experience on their experiences of SDM, we conducted multiple logistic regression analysis with CollaboRATE top score as the outcome variable. ${ }^{38}$ The highest possible CollaboRATE scores (ie, 27 ) were coded with a value of ' 1 '; all lower scores were coded ' 0 '. We calculated the average predicted probability of obtaining a CollaboRATE score adjusting for all other variables in the model. The top score is a validated method of scoring CollaboRATE and allows more meaningful interpretation of the score, namely, the proportion of consumers who perceived a highest possible quality SDM process compared with those who felt there was some room for improvement.

Individual item analysis used pairwise deletion, while the regression analysis used listwise deletion. Analyses were conducted using Stata V.13 (StataCorp LP, College Station, Texas, USA). All tests were considered statistically significant at $\mathrm{p} \leq 0.05$.

\section{Sample size}

We planned to recruit a sample of 1000 consumers, which in a similarly sized probability sample would provide $95 \%$ confidence of estimating the population's information priorities to within $\pm 3 \%$. This also allowed for a minimum of 10 observations per parameter in the multiple logistic regression model of CollaboRATE top scores. ${ }^{39}$ We targeted a minimum of 30 responses per clinician specialty and purposefully sought more primary care physicians than psychiatrists, as approximately $30 \%$ 
Table 1 Demographic profile of consumer respondents

\section{Characteristic}

Number of

Age, years

18-29

30-39

$40-49$

$50-59$

$60-69$

$70+$

Gender

Female

Male

Other

Education

Less than college

Some college/college degree

Graduate/professional degree

Prefer not to say

Employment status

Employed

Not employed

Marital status

Married

Single (never married)

Separated or divorced

Widowed

Prefer not to say

Community environment (residence) Urban/metropolitan (50 $000+)$

Large rural city/micropolitan

(10 000-49 999)

Small rural city/town (2500-9999) $170(23)$

Isolated rural town (under 2500,

$60+$ min to urban area)

Race $^{*}$

White

American Indian or Alaska Native

African-American

Asian

Native Hawaiian or Pacific Islander

Other

Ethnicity

Not Hispanic/Latino

Hispanic/Latino

Language spoken at home

English

Other

Health insurance status

Insured through my current or

former employer

Insured through a family member's

current or former employer

Insured through a public

programme (eg, Medicare,

Medicaid, CHIP)

Insured through a government

exchange

Insured directly from an insurance company
Table 1 Continued

\begin{tabular}{ll}
\hline Characteristic & $\begin{array}{l}\text { Number of } \\
\text { consumers (\%) }\end{array}$ \\
\hline Not insured & $88(12)$ \\
Other & $28(4)$ \\
Prefer not to say & $18(2)$ \\
Mental health comorbidities* & $n=953$ \\
Anxiety disorder & $649(68)$ \\
Post-traumatic stress disorder & $285(30)$ \\
Obsessive-compulsive disorder & $145(15)$ \\
Other & $466(49)$ \\
None & $133(14)$ \\
Other long-term health conditions ${ }^{*}$ & $n=925$ \\
Hypertension & $82(9)$ \\
Diabetes/prediabetes & $78(8)$ \\
Arthritis & $41(4)$ \\
Asthma & $38(4)$ \\
Fibromyalgia & $34(4)$ \\
Other & $442(48)$ \\
None & $513(55)$ \\
\hline
\end{tabular}

${ }^{*}$ Multiple selections allowed.

CHIP, Children's Health Insurance Program.

of all outpatient visits (initial or follow-up) for depressive disorders occur in primary care. ${ }^{40}$

\section{RESULTS}

\section{Participants}

In total, 1557 consumers began the survey, 1096 met all eligibility criteria and 972 attempted to answer survey questions. For the 972 consumers who attempted survey questions, median completion time was $12 \mathrm{~min}$. Five consumers spent longer than $24 \mathrm{~h}$ on the survey. In total, 471 clinicians began the survey, of whom 300 met all eligibility criteria and 244 attempted to answer survey questions. Clinicians' median completion time was $11 \mathrm{~min}$, with one clinician spending longer than $24 \mathrm{~h}$ on the survey.

The sociodemographic profile of consumer respondents (table 1) approximated lifetime prevalence of major depressive disorder in the USA on age and gender. ${ }^{31}$ Consumer respondents were mostly female $(\mathrm{n}=664 / 967 ; 69 \%)$, Caucasian $(\mathrm{n}=716 / 776 ; 92 \%)$ and covered a diverse range of ages (mean 43.17, SD 13.41). Many had comorbid anxiety disorders ( $\mathrm{n}=649 / 953$; $67 \%)$ and a majority had at least some postsecondary education $(\mathrm{n}=615 / 786 ; 79 \%)$.

Consumer respondents were predominantly still in treatment $(\mathrm{n}=756 / 972 ; 78 \%)$ and reported their principal clinicians to be therapists $(n=338 / 968 ; 35 \%)$, psychiatrists $(n=327 / 968 ; 34 \%)$ or primary care physicians $(n=235 / 968 ; 24 \%)$. Antidepressants were the most common treatment used $(\mathrm{n}=901 / 970 ; 93 \%)$, with talk therapy $(\mathrm{n}=703 / 970 ; 72 \%)$ and lifestyle changes $(\mathrm{n}=412 / 970 ; 42 \%)$ also commonly reported (table 2$)$.

Clinician respondents were distributed across a variety of clinical specialties, with therapists $(n=109$ / 
Table 2 Demographic profile of clinician respondents

\begin{tabular}{|c|c|}
\hline Characteristic & $\begin{array}{l}\text { Number of } \\
\text { clinicians (\%) }\end{array}$ \\
\hline Specialty & $n=244$ \\
\hline Therapist* ${ }^{*}$ & $109(45)$ \\
\hline $\begin{array}{l}\text { Primary care/internal medicine } \\
\text { physician }\end{array}$ & $81(33)$ \\
\hline Psychiatrist & $25(10)$ \\
\hline Psychiatric/mental health nurse & $6(3)$ \\
\hline Other & $23(9)$ \\
\hline $\begin{array}{l}\text { Proportion of past year's clients with } \\
\text { depression }\end{array}$ & $n=243$ \\
\hline A majority & $67(28)$ \\
\hline A substantial portion & $151(62)$ \\
\hline Few & $25(10)$ \\
\hline Preferred treatment & $n=241$ \\
\hline $\begin{array}{l}\text { Combination talk therapy and } \\
\text { medication }\end{array}$ & $75(31)$ \\
\hline Talk therapy & $75(31)$ \\
\hline Antidepressant medication & $65(27)$ \\
\hline Lifestyle changes & $18(7)$ \\
\hline Alternative therapy & $6(2)$ \\
\hline Electroconvulsive therapy & $2(1)$ \\
\hline Community environment (workplace) & $n=205$ \\
\hline Urban/metropolitan (50 000+) & $84(41)$ \\
\hline $\begin{array}{l}\text { Large rural city/micropolitan } \\
\text { (10 000-49 999) }\end{array}$ & $53(26)$ \\
\hline Small rural city/town (2500-9999) & $61(30)$ \\
\hline $\begin{array}{l}\text { Isolated rural town (under } 2500 \text {, } \\
60+\text { min to urban area) }\end{array}$ & $7(3)$ \\
\hline Race† & $n=204$ \\
\hline White & $179(88)$ \\
\hline Asian & $18(9)$ \\
\hline African-American & $6(3)$ \\
\hline American Indian or Alaska Native & $4(2)$ \\
\hline Native Hawaiian or Pacific Islander & $0(0)$ \\
\hline Other & $1(0)$ \\
\hline Ethnicity & $n=203$ \\
\hline Not Hispanic/Latino & $194(96)$ \\
\hline Hispanic/Latino & $9(4)$ \\
\hline Language spoken at home & $n=243$ \\
\hline English & $212(87)$ \\
\hline Other & $31(13)$ \\
\hline
\end{tabular}

*'Therapist' describes non-prescribing clinicians including psychologist, social worker and licensed professional counsellor. †Multiple selections allowed.

$244 ; 45 \%)$, primary care physicians $(\mathrm{n}=81 / 244 ; 33 \%)$, psychiatrists $(\mathrm{n}=25 / 244 ; 10 \%)$ and other clinicians $(n=29 / 244 ; 11 \%)$ represented (table 3$)$. On average, clinician respondents had 15.08 years professional experience (SD 10.96). All had treated individuals for depression in the past year, with $90 \%$ reporting that at least a substantial portion of their clients has depression. Combination therapy $(\mathrm{n}=75 / 241 ; 31 \%)$, talk therapy $(\mathrm{n}=75 / 241 ; 31 \%)$ and antidepressant medications $(\mathrm{n}=65 / 241 ; 27 \%)$ were clinicians' most frequent treatment approaches. Primary care practitioner (PCPs) made more frequent use of antidepressant medications than did other clinician types. When comparing
Table 3 Consumer treatment experience

\begin{tabular}{ll}
\hline Characteristic & $\begin{array}{l}\text { Number of } \\
\text { consumers (\%) }\end{array}$ \\
\hline Treatment status & $n=972$ \\
Currently in treatment & $756(78)$ \\
Treated in the past & $169(17)$ \\
Awaiting treatment & $47(5)$ \\
Primary treating clinician & $n=968$ \\
Therapist or psychologist & $338(35)$ \\
Psychiatrist & $327(34)$ \\
Primary care doctor & $235(24)$ \\
Other & $47(5)$ \\
Not sure & $21(2)$ \\
Most recent consultation about & $n=789$ \\
depression & \\
Less than a week ago & $183(23)$ \\
1 week to 1 month ago & $222(28)$ \\
1-6 months ago & $214(27)$ \\
6-12 months ago & $60(8)$ \\
12 or more months ago & $110(14)$ \\
Treatments used (lifetime) & $n=970$ \\
Antidepressant medication & $901(93)$ \\
Talk therapy & $703(72)$ \\
Lifestyle changes & $412(42)$ \\
Alternative therapy & $141(15)$ \\
Electroconvulsive therapy & $46(5)$ \\
Deep brain stimulation & $9(1)$ \\
\hline *Multiple selections allowed. & \\
&
\end{tabular}

prescribers (PCPs and psychiatrists) to non-prescribers (therapists), prescribers say they most often request antidepressants alone (55\%) followed by combination therapy (33\%) and talk therapy (3\%), while nonprescribers instead favour talk therapy (59\%) and combination therapy $(34 \%)$ over solely medication $(1 \%)$.

\section{What matters most in treatment decision-making \\ Consumer perspective}

The 742 consumers who answered ranking questions felt the most important information when making a treatment decision was 'Will the treatment work?', followed by 'What are the side effects of this treatment?', 'Is the treatment covered by insurance?', 'How long before I feel better?' and 'How much does this treatment cost?' (table 4). Consumers' most concerning potential side effect was increased risk of suicide, followed by sleep issues, weight change, heart problems and increased stress (see online supplementary appendix 4$)$.

Importance rankings did not show evidence of variation by consumer age, gender or educational attainment (analysis available on request).

\section{Clinician perspective: What consumers need to know}

Two hundred and two clinicians completed rankings of what they perceived to be most important in depression treatment decisions. When considering the information priorities from their professional perspectives, clinicians 


\begin{tabular}{|c|c|c|c|}
\hline & Information priority & $\begin{array}{l}\text { Weighted } \\
\text { score }\end{array}$ & $\mathbf{N}$ \\
\hline \multicolumn{4}{|c|}{ Clinicians, from clinician perspective } \\
\hline \#1 & Will the treatment work? & 566 & \\
\hline \#2 & $\begin{array}{l}\text { How long before the } \\
\text { patient feels better? }\end{array}$ & 348 & \\
\hline \#3 & $\begin{array}{l}\text { What are the side effects } \\
\text { of this treatment? }\end{array}$ & 318 & \\
\hline$\# 4$ & $\begin{array}{l}\text { How does the treatment } \\
\text { work? }\end{array}$ & 242 & \\
\hline \#5 & $\begin{array}{l}\text { What is involved in using } \\
\text { the treatment? }\end{array}$ & 224 & \\
\hline Total & & & 202 \\
\hline \multicolumn{4}{|c|}{ Clinicians, from patient perspective } \\
\hline$\# 1$ & Will the treatment work? & 469 & \\
\hline \#2 & $\begin{array}{l}\text { How long before the } \\
\text { patient feels better? }\end{array}$ & 380 & \\
\hline \#3 & $\begin{array}{l}\text { How much does the } \\
\text { treatment cost? }\end{array}$ & 266 & \\
\hline \#4(tie) & $\begin{array}{l}\text { Is the treatment covered } \\
\text { by insurance? }\end{array}$ & 232 & \\
\hline \#4(tie) & $\begin{array}{l}\text { What are the side effects } \\
\text { of this treatment? }\end{array}$ & 232 & \\
\hline Total & & & 172 \\
\hline \multicolumn{4}{|l|}{ Patients } \\
\hline$\# 1$ & Will the treatment work? & 1524 & \\
\hline \#2 & $\begin{array}{l}\text { What are the side effects } \\
\text { of this treatment? }\end{array}$ & 1407 & \\
\hline \#3 & $\begin{array}{l}\text { Is the treatment covered } \\
\text { by insurance? }\end{array}$ & 1224 & \\
\hline \#4 & $\begin{array}{l}\text { How long before I feel } \\
\text { better? }\end{array}$ & 1147 & \\
\hline \#5 & $\begin{array}{l}\text { How much does this } \\
\text { treatment cost? }\end{array}$ & 984 & \\
\hline Total & & & 782 \\
\hline
\end{tabular}

ranked 'Will the treatment work?' first, followed by 'How long before the patient feels better?', 'What are the side effects of this treatment?', 'How does the treatment work?' and 'What is involved in using the treatment?' (table 4). These information priorities diverged from those of consumers in the area of cost and insurance coverage.

Slight differences in information priority rankings by clinician type are outlined in online supplementary appendix 5. PCPs and psychiatrists ranked 'Will this treatment affect other existing health conditions?' much higher than therapists. Psychiatrists and therapists ranked 'What is involved in using this treatment?' higher than PCPs, while 'How much does the treatment cost?' was ranked higher by PCPs than by psychiatrists or therapists. The most concerning potential side effect for clinicians was increased risk of suicide, followed by drug-drug interactions, heart problems, weight change and sexual issues (see online supplementary appendix 2).
Clinician perspective: What consumers want to know

One hundred and seventy-two clinicians completed rankings of what they believe their clients find most important when making a treatment decision. When considering the importance of the information priorities from a consumer's perspective, clinicians included the same priorities as consumers but in a different order (table 4). 'Will the treatment work?' again ranked number 1 , followed by 'How long before the patient feels better?', 'How much does the treatment cost?', 'Is the treatment covered by insurance?' and 'What are the side effects of this treatment?'. No evidence was found for significant differences by clinician type (see online supplementary appendix 4).

\section{Engagement in care}

Only $18 \% \quad(n=144 / 781)$ of consumers reported a CollaboRATE top score, indicating that a majority of consumer respondents perceived low levels of SDM in their most recent clinical encounters. Many consumers $(n=405 / 789 ; 51 \%)$ had their most recent visits within the previous month (table 2).

CollaboRATE top scores were more likely where the respondents were female (OR 2.14, $\mathrm{p}=0.003$ ) or where they worked with a psychiatrist (OR 1.91, $\mathrm{p}=0.025$; table 5). Respondents in older age groups appeared more likely to report a CollaboRATE top score compared with those under 30 years old, with statistically significant associations found in the 40-49 years old and over 60 years old groups (table 5 ). Yet when age was analysed as a continuous variable, no association between age and CollaboRATE top score was found (analysis available on request). The probability of a CollaboRATE top score where a consumer worked with a psychiatrist was $24.5 \%(95 \%$ CI $18.7 \%$ to $30.3 \%), 18.5 \%$ when working with a therapist (95\% CI $13.4 \%$ to $23.6 \%)$ and $14.8 \%$ when working with a primary care physician (95\% CI $8.9 \%$ to $20.7 \%$ ). The predicted probability of females reporting a CollaboRATE top score was $22.0 \%$ (95\% CI $18.2 \%$ to $25.9 \%)$ compared with males, $12.2 \%$ $(95 \%$ CI $7.4 \%$ to $16.9 \%)$.

\section{DISCUSSION}

The information priorities of individuals with depression in the USA are not always aligned with those of clinicians. Consumers and clinicians agree that effectiveness of treatment, side effects and speed of recovery are important. While treatment costs and insurance coverage are a higher priority for consumers, explanations of how a treatment should be used and how it works were more important for clinicians. However, when clinicians were asked to adopt a consumer perspective, they were able to reliably report what consumers view to be most important. For side effect rankings, there was close alignment between consumers and clinicians; however, unlike clinicians, consumers included sleep issues and increased stress related to treatment among the most 
Table 5 Analysis of CollaboRATE top scores

\begin{tabular}{|c|c|c|c|c|}
\hline & $\begin{array}{l}\text { Unadjusted } \\
\text { regression }\end{array}$ & $\begin{array}{l}\text { Adjusted } \\
\text { regression }\end{array}$ & $\begin{array}{l}\text { Unadjusted } \\
\text { proportion (n) }\end{array}$ & $\begin{array}{l}\text { Adjusted predicted } \\
\text { proportion }(95 \% \mathrm{Cl})\end{array}$ \\
\hline \multicolumn{5}{|l|}{ Clinician most frequently seen } \\
\hline Primary care physician & 1.00 (reference) & 1.00 (reference) & $14 \%(25)$ & 15 (9 to 21$)$ \\
\hline Psychiatrist & 1.80 (1.08 to 3.00$)$ & $1.87(1.07$ to 3.26$)$ & $23 \%(62)$ & 24 (19 to 30$)$ \\
\hline Therapist & 1.39 (0.82 to 2.34$)$ & $1.31(0.73$ to 2.34$)$ & $19 \%(51)$ & 19 (13 to 24$)$ \\
\hline Other/not sure & $0.72(0.28$ to 1.87$)$ & 0.80 (0.30 to 2.13$)$ & $11 \%(6)$ & 12 (3 to 21$)$ \\
\hline \multicolumn{5}{|l|}{ Age } \\
\hline $18-29$ & 1.00 (reference) & 1.00 (reference) & $13 \%(19)$ & 13 (7 to 19$)$ \\
\hline 30-39 & $1.82(0.99$ to 3.35$)$ & $1.85(0.96$ to 3.54$)$ & $21 \%(34)$ & 21 (14 to 28$)$ \\
\hline $40-49$ & 2.26 (1.26 to 4.03$)$ & 2.10 (1.11 to 3.97$)$ & $24 \%(48)$ & $23(17$ to 30$)$ \\
\hline $50-59$ & 1.09 (0.58 to 2.09$)$ & $1.24(0.62$ to 2.48$)$ & $14 \%(24)$ & 15 (9 to 21$)$ \\
\hline $60+$ & 2.05 (1.01 to 4.13$)$ & 2.49 (1.14 to 5.43$)$ & $23 \%(19)$ & 27 (16 to 37 \\
\hline \multicolumn{5}{|l|}{ Treatments used } \\
\hline Antidepressant medication only & 1.00 (reference) & 1.00 (reference) & $12 \%(14)$ & 14 (7 to 22$)$ \\
\hline Medication and other treatment & $1.92(1.06$ to 3.46$)$ & $1.52(0.80$ to 2.91$)$ & $20 \%(124)$ & $20(17$ to 24$)$ \\
\hline Non-medication treatment & $0.99(0.36$ to 2.74$)$ & $0.93(0.29$ to 3.00$)$ & $12 \%(6)$ & 13 (2 to 25$)$ \\
\hline \multicolumn{5}{|l|}{ Gender } \\
\hline Male & 1.00 (reference) & 1.00 (reference) & $12 \%(25)$ & 12 (7 to 17$)$ \\
\hline Female & 2.00 (1.26 to 3.18$)$ & 2.04 (1.24 to 3.34$)$ & $21 \%(119)$ & 22 (18 to 26$)$ \\
\hline \multicolumn{5}{|l|}{ Treatment status } \\
\hline Currently being treated & 1.00 (reference) & 1.00 (reference) & $19 \%(118)$ & 19 (15 to 22$)$ \\
\hline Awaiting treatment & $0.87(0.35$ to 2.14$)$ & $0.93(0.33$ to 2.62$)$ & $17 \%(6)$ & 18 (3 to 33$)$ \\
\hline Treated in the past & $0.78(0.47$ to 1.32$)$ & $0.98(0.56$ to 1.71$)$ & $16 \%(20)$ & 19 (11 to 26$)$ \\
\hline \multicolumn{5}{|l|}{ Education level } \\
\hline High school or less & 1.00 (reference) & 1.00 (reference) & $20 \%(31)$ & 22 (15 to 29$)$ \\
\hline Some college to Bachelor's degree & $0.93(0.59$ to 1.47$)$ & $0.77(0.47$ to 1.27$)$ & $19 \%(85)$ & 18 (14 to 22$)$ \\
\hline Graduate/professional degree & $0.96(0.54$ to 1.69$)$ & $0.77(0.42$ to 1.44$)$ & $19 \%(28)$ & 18 (11 to 25$)$ \\
\hline \multicolumn{5}{|l|}{ Health insurance status } \\
\hline Private health insurance & 1.00 (reference) & 1.00 (reference) & $19 \%(86)$ & 19 (15 to 23$)$ \\
\hline Public health insurance & $1.22(0.78$ to 1.90$)$ & $1.06(0.66$ to 1.71$)$ & $23 \%(35)$ & 20 (13 to 26$)$ \\
\hline No insurance & $0.88(0.48$ to 1.61$)$ & 0.89 (0.47 to 1.69$)$ & $17 \%(15)$ & 17 (9 to 25$)$ \\
\hline
\end{tabular}

concerning side effects. A lack of SDM observed in the context of depression treatment decisions may explain this misalignment in information priorities.

\section{Interpretation of findings}

This is the first study to identify and compare consumers' and clinicians' information priorities when considering depression treatment decisions. It is reassuring to find alignment in several areas and promising to observe that clinicians are aware of consumer information priorities. However, clinicians do not prioritise insurance and cost information, despite realising its importance to consumers. The importance of cost and insurance information to consumers is consistent with previous literature. $^{41} 42$ The low priority we found clinicians give to cost and insurance coverage information supports previous research on frequency of clinician-consumer communication about out-of-pocket costs. ${ }^{43}$ This lack of communication has been attributed to time limitations within clinical encounters, the challenge of identifying consumer-specific costs, and a belief that medical decisions should be based exclusively on needs, not costs. $^{44}{ }^{45}$ Yet the cost of treatment has a significant impact on consumer well-being, financial stability, adherence and eventual health status. ${ }^{46}$

In contrast to other studies across many conditions ${ }^{47} 48$ where CollaboRATE scores average around 70\%, only $18 \%$ of individuals with depression reported a top score on CollaboRATE. Our findings support previous studies where consumers with depression report low SDM in primary care and extend this result to other clinical specialties. $^{22} 23$ Female consumers were more likely to report higher CollaboRATE scores. This may be explained by previous research indicating females' preference for more active roles in decision-making. ${ }^{49}$ While SDM was low across all clinician types, primary care physicians scored significantly lower than psychiatrists. These low scores may result from additional time pressures, as Tai-Seale et $a l^{50}$ reported that a sample of primary care clinicians treating patients with mental health needs spent on average only 2 min per visit on mental health issues. Despite these differences in CollaboRATE scores by clinician type, we can conclude that consumers generally perceived low levels of SDM. 


\section{Strengths and limitations}

Though our convenience sampling approach eliminates confidentiality concerns associated with preidentifying individuals with depression across the USA, we are as a result unable to determine response rates and lack true representativeness; a probability sample would address this concern. However, by ensuring that the respondent sample approximated epidemiological data on lifetime depression prevalence with regard to age and gender, we reduced the potential impact of selection bias. In addition, clinicians in our survey are likely to treat a broad spectrum of individuals with depression; therefore, a wide range of consumers inform their views of what is most important to consumers. That these views match the views prioritised by the consumer sample is reassuring. As we were unable to target clinician sampling due to a lack of relevant data, the potential for selection bias remains a concern.

Additionally, independent clinician and consumer samples preclude direct comparisons between the groups. Further research is needed to address convergence or divergence of information priorities within clinician-consumer dyads. However, broad inclusion criteria for consumers and clinicians enabled thorough representation of depression care in the USA, evident by consumer responses from 49 of 50 US states and the District of Columbia.

\section{Implications}

While clinicians are aware of what matters most to consumers with depression, they do not always prioritise this information. Low SDM combined with a misalignment in information priorities between consumers and clinicians may explain why consumers often do not receive their preferred treatments. ${ }^{51}$

Better equipping clinicians to talk to consumers about information central to consumer decision-making, such as the cost and insurance coverage associated with different treatment options, can lead to more engaged and empowered consumers. This is of particular interest given the expansion of mental health coverage and depression screening resulting from the Patient Protection and Affordable Care Act. Despite previous research finding an association between SDM and higher consumer satisfaction in depression care $^{21}$ routine clinician training in SDM is still lacking. The current work can help inform development of a DESI for depression that consists of key information priorities identified by consumers and clinicians. These tools have demonstrated promise in treating other conditions and may help facilitate clinician-consumer conversations in depression care, leading to better informed consumers choosing treatments that are right for them. We are currently in the process of developing a DESI based on our findings and testing understanding, comprehensiveness and acceptability with key stakeholders (consumers, general public and clinicians) through cognitive interviews.

\section{CONCLUSION}

While consumers and clinicians agreed on some information priorities for depression treatment decisionmaking, there was misalignment in the area of treatment cost and insurance coverage despite clinician awareness of the importance of these issues to consumers. The low levels of SDM reported by consumers with depression emphasise the impact of this priority mismatch. Future work on interventions to improve depression treatment decision-making may help narrow the existing gap between consumers' and clinicians' information priorities and increase SDM, leading to treatments aligned with consumer preferences.

Twitter Follow Paul Barr at @BarrPaulJ

Acknowledgements The authors thank the following individuals and groups for their contributions to our study: Jim Matthews for comments on the manuscript; Bob Drake and Mark Hegel of Dartmouth College for feedback and advice on initial drafts of the surveys; Greg McHugo of Dartmouth College for advice on study design; James 0'Malley for advice on data analysis; and organisations listed in online supplementary appendix 1 for help with recruitment.

Contributors PJB conceived of the study and contributed to the design of the work, interpretation of data, and drafting and revision of the manuscript. RCF contributed to the design of the work, data analysis, interpretation of data and drafting and revision of the manuscript. MM contributed to the design of the work, interpretation of data and revision of the manuscript. RB contributed to the design of the work and drafting of the manuscript. GE contributed to the design of the work and drafting and revision of the manuscript.

Funding This research received no specific grant from any funding agency in the public, commercial or not-for-profit sectors.

Competing interests GE reports grants and personal fees from the Informed Medical Decision Making Foundation, personal fees from Emmi Solutions LLC, outside the submitted work. As two of the copyright holders of CollaboRATE, GE and PJB wish to declare this intellectual conflict of interest. CollaboRATE is freely available under a Creative Commons License for non-commercial use: CC BY-NC-ND 3.0 Unported. GE also wishes to declare an intellectual competing interests as the founder of the Option Grid Collaborative. Option Grids are freely available under a Creative Commons License for non-commercial use: CC BY-NC-ND 4.0.

Ethics approval Dartmouth College Committee for the Protection of Human Subjects.

Provenance and peer review Not commissioned; externally peer reviewed.

Data sharing statement No additional data are available.

Open Access This is an Open Access article distributed in accordance with the Creative Commons Attribution Non Commercial (CC BY-NC 4.0) license, which permits others to distribute, remix, adapt, build upon this work noncommercially, and license their derivative works on different terms, provided the original work is properly cited and the use is non-commercial. See: http:// creativecommons.org/licenses/by-nc/4.0/

\section{REFERENCES}

1. Anderson IM. Meta-analytical studies on new antidepressants. Br Med Bull 2001;57:161-78.

2. Butler AC, Chapman JE, Forman EM, et al. The empirical status of cognitive-behavioral therapy: a review of meta-analyses. Clin Psychol Rev 2006;26:17-31.

3. Barth J, Munder T, Gerger $\mathrm{H}$, et al. Comparative efficacy of seven psychotherapeutic interventions for patients with depression: a network meta-analysis. PLoS Med 2013;10:e1001454.

4. Cuijpers P, Berking M, Andersson G, et al. A meta-analysis of cognitive-behavioural therapy for adult depression, alone and in 
comparison with other treatments. Can J Psychiatry 2013:58:376-85.

5. Richards D, Richardson T. Computer-based psychological treatments for depression: a systematic review and meta-analysis. Clin Psychol Rev 2012;32:329-42.

6. Turner EH, Matthews AM, Linardatos E, et al. Selective publication of antidepressant trials and its influence on apparent efficacy. $N$ Engl $J$ Med 2008;358:252-60.

7. Bet PM, Hugtenburg JG, Penninx BWJH, et al. Side effects of antidepressants during long-term use in a naturalistic setting. Eur Neuropsychopharmacol 2013;23:1443-51.

8. Hu XH, Bull SA, Hunkeler EM, et al. Incidence and duration of side effects and those rated as bothersome with selective serotonin reuptake inhibitor treatment for depression: patient report versus physician estimate. J Clin Psychiatry 2004;65:959-65.

9. Van Schaik DJF, Klijn AFJ, van Hout HPJ, et al. Patients' preferences in the treatment of depressive disorder in primary care. Gen Hosp Psychiatry 2004;26:184-9.

10. Marcus SC, Olfson M. National trends in the treatment for depression from 1998 to 2007. Arch Gen Psychiatry 2010;67:1265-73.

11. Swift JK, Greenberg RP. Premature discontinuation in adult psychotherapy: a meta-analysis. J Consult Clin Psychol 2012;80:547-59.

12. Peveler R, George C, Kinmonth A-L, et al. Effect of antidepressant drug counselling and information leaflets on adherence to drug treatment in primary care: randomised controlled trial. $B M J$ 1999;319:612-15.

13. Cantrell CR, Eaddy MT, Shah MB, et al. Methods for evaluating patient adherence to antidepressant therapy: a real-world comparison of adherence and economic outcomes. Med Care 2006;44:300-3.

14. Pampallona S, Bollini $\mathrm{P}$, Tibaldi G, et al. Patient adherence in the treatment of depression. Br J Psychiatry 2002;180:104-9.

15. Kwan BM, Dimidjian S, Rizvi SL. Treatment preference, engagement, and clinical improvement in pharmacotherapy versus psychotherapy for depression. Behav Res Ther 2010;48:799-804.

16. Rokke PD, Tomhave JA, Jocic $Z$. The role of client choice and target selection in self-management therapy for depression in older adults. Psychol Aging 1999;14:155-69.

17. Lin P, Campbell DG, Chaney EF, et al. The influence of patient preference on depression treatment in primary care. Ann Behav Med 2005;30:164-73.

18. Lindhiem O, Bennett CB, Trentacosta CJ, et al. Client preferences affect treatment satisfaction, completion, and clinical outcome: a meta-analysis. Clin Psychol Rev 2014;34:506-17.

19. Raue PJ, Schulberg HC, Lewis-Fernandez R, et al. Shared decision-making in the primary care treatment of late-life major depression: a needed new intervention? Int J Geriatr Psychiatry 2010;25:1101-11.

20. Christensen H, Griffiths KM, Gulliver A, et al. Models in the delivery of depression care: a systematic review of randomised and controlled intervention trials. BMC Fam Pract 2008:9:25.

21. Swanson KA, Bastani R, Rubenstein LV, et al. Effect of mental health care and shared decision making on patient satisfaction in a community sample of patients with depression. Med Care Res Rev 2007;64:416-30

22. Solberg LI, Crain AL, Rubenstein L, et al. How much shared decision making occurs in usual primary care of depression? J Am Board Fam Med 2014;27:199-208.

23. Young HN, Bell RA, Epstein RM, et al. Physicians' shared decision-making behaviors in depression care. Arch Intern Med 2008;168:1404-8

24. Simmons MB, Hetrick SE, Jorm AF. Experiences of treatment decision making for young people diagnosed with depressive disorders: a qualitative study in primary care and specialist mental health settings. BMC Psychiatry 2011;11:194.

25. Clever SL, Ford DE, Rubenstein LV, et al. Primary care patients' involvement in decision-making is associated with improvement in depression. Med Care 2006;44:398-405.

26. Stacey D, Légaré $\mathrm{F}$, Col NF, et al. Decision aids for people facing health treatment or screening decisions. Cochrane Database Syst Rev 2014;1:CD001431.
27. Wyatt KD, Branda ME, Inselman JW, et al. Genders of patients and clinicians and their effect on shared decision making: a participant-level meta-analysis. BMC Med Inform Decis Mak 2014;14:81.

28. Duncan E, Best C, Hagen S. Shared decision making interventions for people with mental health conditions. Cochrane Database Syst Rev 2010;(1):CD007297.

29. LeBlanc A, Herrin J, Williams MD, et al. Shared decision making for antidepressants in primary care: a cluster randomized trial. JAMA Intern Med 2015;175:1761-70.

30. Loh A, Simon D, Wills CE, et al. The effects of a shared decisionmaking intervention in primary care of depression: a clusterrandomized controlled trial. Patient Educ Couns 2007;67:324-32.

31. Hasin DS, Goodwin RD, Stinson FS, et al. Epidemiology of major depressive disorder: results from the National Epidemiologic Survey on Alcoholism and Related Conditions. Arch Gen Psychiatry 2005;62:1097-106.

32. Donnelly KZ, Foster TC, Thompson R. What matters most? The content and concordance of patients' and providers' information priorities for contraceptive decision making. Contraception 2014;90:280-7.

33. Ryan C. Language use in the United States: 2011. US Census Bureau, 2013

34. About Educational Attainment-US Census Bureau. https://www. census.gov/hhes/socdemo/education/about/ (accessed 30 Oct 2015)

35. Humes KR, Jones NA, Ramirez RR. Overview of race and Hispanic origin: 2010. US Census Bureau, 2011

36. Kreider RM, Simmons T. Marital status: 2000. US Census Bureau, 2003.

37. Elwyn G, Barr PJ, Grande SW, et al. Developing CollaboRATE: a fast and frugal patient-reported measure of shared decision making in clinical encounters. Patient Educ Couns 2013;93:102-7.

38. Barr PJ, Thompson R, Walsh T, et al. The psychometric properties of CollaboRATE: a fast and frugal patient-reported measure of the shared decision-making process. J Med Internet Res 2014;16:e2.

39. Peduzzi P, Concato J, Kemper E, et al. A simulation study of the number of events per variable in logistic regression analysis. $J$ Clin Epidemiol 1996;49:1373-9.

40. Centers for Disease Control and Prevention. Selected patient and provider characteristics for ambulatory care visits to physician offices and hospital outpatient and emergency departments: United States, 2009-2010. FastStats. 2010. http://www.cdc.gov/nchs/data/ahcd/ combined_tables/AMC_2009-2010_combined_web_table01.pdf (accessed 9 Jun 2015)

41. Dunlea R, Lenert L. Understanding patients' preferences for referrals to specialists for an asymptomatic condition. Med Decis Making 2015;35:691-702

42. Tseng C-W, Waitzfelder BE, Tierney EF, et al. Patients' willingness to discuss trade-offs to lower their out-of-pocket drug costs. Arch Intern Med 2010;170:1502-4.

43. Alexander GC, Casalino LP, Meltzer DO. Patient-physician communication about out-of-pocket costs. JAMA 2003;290:953-8.

44. Alexander GC, Casalino LP, Tseng C-W, et al. Barriers to patient-physician communication about out-of-pocket costs. J Gen Intern Med 2004;19:856-60.

45. Blumenthal-Barby JS, Robinson E, Cantor SB, et al. The neglected topic: presentation of cost information in patient decision AIDS. Med Decis Making 2015;35:412-18.

46. Ubel PA, Abernethy AP, Zafar SY. Full disclosure-out-of-pocket costs as side effects. N Engl J Med 2013;369:1484-6.

47. Barr PJ, Thompson R, Forcino RC, et al. Implementing CollaboRATE in primary care: an interim analysis. International Shared Decision Making Conference; 2015.

48. Thompson R, Nye A, Walker E, et al. From bariatric surgery to vasectomy: how much shared decision making takes place in routine health care? International Shared Decision Making Conference; 2015.

49. Arora NK, McHorney CA. Patient preferences for medical decision making: who really wants to participate? Med Care 2000;38:335-41.

50. Tai-Seale M, Foo PK, Stults CD. Patients with mental health needs are engaged in asking questions, but physicians' responses vary. Health Aff (Millwood) 2013;32:259-67.

51. Dwight-Johnson M, Unutzer J, Sherbourne C, et al. Can quality improvement programs for depression in primary care address patient preferences for treatment? Med Care 2001;39:934-44. 